\title{
Evaluation of road safety performance at micro level using grey data
}

\author{
Mirjana Grdinić-Rakonjac ${ }^{a^{*}}$, Boris Antićb ${ }^{\text {, Vladimir Pajkovića }}{ }^{a}$ \\ ${ }^{a}$ Faculty of Mechanical Engineering, University of Montenegro, Podgorica, Montenegro \\ ${ }^{b}$ Faculty of Transport and Traffic Engineering, University of Belgrade, Belgrade, Serbia
}

\begin{tabular}{|c|c|}
\hline ARTICLE INFO & A B S T R A C T \\
\hline $\begin{array}{l}\text { DOI: } 10.31075 / \text { PIS.66.03.03 } \\
\text { Professional paper } \\
\text { Received: } 01.09 .2020 \\
\text { Accepted:30.09.2020 } \\
\text { Corresponding author: } \\
\text { e-mail: grdinicm@ucg.ac.me } \\
\text { Keywords: }\end{array}$ & $\begin{array}{l}\text { The aim of the study is to access road safety evaluation at micro level. Data } \\
\text { Envelopment Analysis (DEA) is integrated with Grey Relational Analysis (GRA) } \\
\text { in order to describe municipalities' road safety providing a more reasonable and } \\
\text { encompassing performance based on which the overall ranking position of } \\
\text { municipalities is obtained. }\end{array}$ \\
\hline $\begin{array}{l}\text { Grey relational analysis } \\
\text { Data envelopment analysis } \\
\text { Grey data }\end{array}$ & \\
\hline
\end{tabular}

\section{Introduction}

Traffic injuries and road deaths remain one of the leading causes of death by injury according to WHO (2018). In addition, many countries lunched different action plans with main goal to halve the number of road accidents and injuries. However, at this point, the goal does not appear to be achieved. Statistics from the EU generally show some progress but stagnation in recent years and the number of 25100 people killed in road accidents in 2018 in the European Union (EC, 2018) means a $21 \%$ decrease in the number of road deaths compared with 2010 when 31500 road deaths were recorded (ETSC, 2011) as it can be seen from figure 1.



Figure 1. Road deaths in EU Source: ETSC, 2019
Montenegro is one of the developing Western Balkan countries in Southeast Europe, with a road density 57.2 $\mathrm{km} / \mathrm{km} 2$ and a high motorization rate of 330 cars per 1.000 inhabitants.

This country is attempting to fulfil the rules and regulations of the EU and adopted the Strategy for improvement of road traffic safety 2010-2019 (Ministry of interior, 2019) with the goal of reducing fatalities by $50 \%$ and injuries by $30 \%$ (compared with 2007) by 2019. By observing a longer period, it can be noted that Montenegro failed to achieve these goals and traffic safety issue remain the problem in each municipality. In 2018, Montenegro recorded a decrease of $50 \%$ in road deaths compared with 2010 and a decrease of approximately 20\% compared with 2011 (all Montenegro data are collected from the Ministry of interior). Road safety is in fact at a low level, with various numbers of people killed in road accidents each year. When translated into fatalities per million inhabitants (figure 2), Montenegro's rate in 2018 is 77, compared with the European average of 49 and with the worstperforming EU countries, namely, Romania (98), Bulgaria (88), Latvia (78) and neighboring Croatia (77), (EC, 2019). Number of accidents and public (number of accidents per 100.000 inhabitants) and traffic risk (number of accidents per 10.000 vehicles) for each municipality in Montenegro are presented in Figure 3 showing that capital city Podgorica reported the highest raw number of accidents (35\% of all accidents) while Kolašin reported the highest relative risks. 
The first step of traffic safety management is to define the current situation in a certain territory and to compare it between different countries and between local regions and communities. Furthermore, influential road safety factors should be identified and based on them, measures should be conducted. In this paper, issue of evaluating safety level of territory has been addressed.

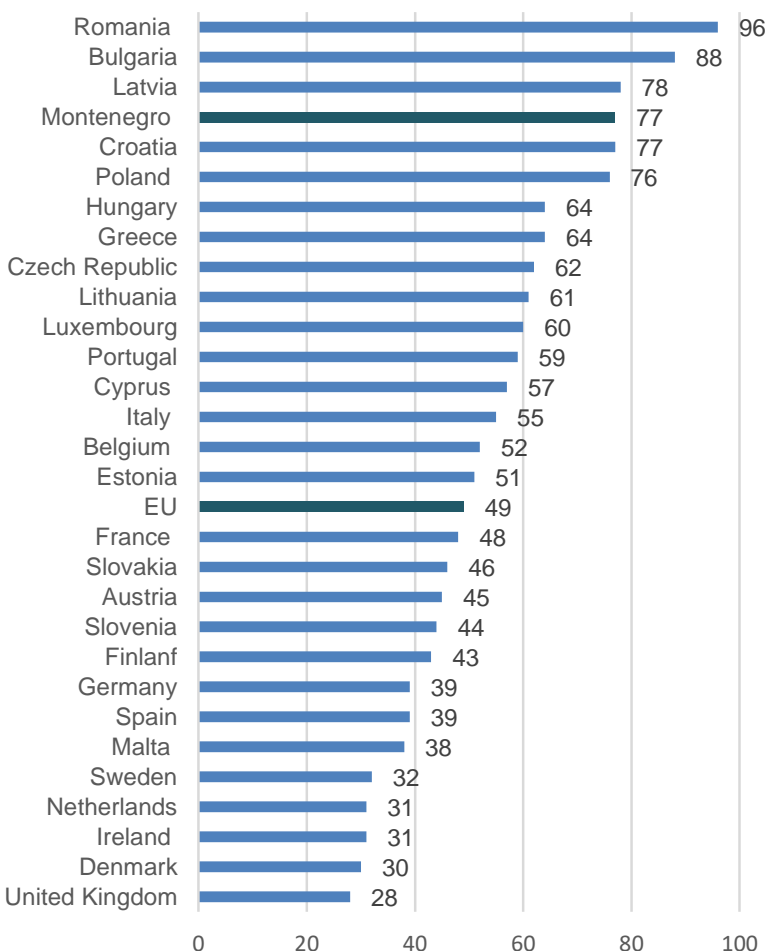

Figure 2. Road fatalities per million inhabitants



Figure 3. Number of accidents by municipalities

\section{Literature review}

Evaluation of road safety is the core of road safety management, and to prevent traffic accidents, an understanding of the factors that cause them is essential. Currently, road safety experts show great interest in finding one fair approach to evaluate and compare road safety situations in different territories.
Aggregation of different variables into one road safety performance index is a popular concept in evaluating road safety and comparing the performance of territories.

No universal approach exists between countries, which consequently results in a large number of methods for index development and benchmarking of road safety. While many other approaches are used for aggregation, recently the most interest is on Data Envelopment Analysis (DEA) for measuring the relative performance in efficiency terms.

DEA, developed by Charnes et al. (1978) and extended by Banker et al. (1984), measures efficiency of entities based on weights which are not priory known. Entities in DEA are so-called the Decision Making Units (DMU) and how they will be classified depends on location relative to efficient frontier. Frontier is formed by the efficient DMUs that represent the best practice. Inefficient DMUs can be compared with efficient which can be observed as benchmarks for further improvement.

An additional problem is the different types of data and depending on the choice of indicator; the compared territories might have different evaluation results. Since indicators might be observed as uncertain systems with partially known and partially unknown information, they can be analyzed with grey relational analysis (GRA). The grey relational analysis is a part of the grey system theory proposed by Deng (1989), which is suitable for solving a variety of multiple attribute decision making problems. GRA refers to the quantitative description and comparison of the developing tendency of a system. Many authors used grey theory to solve multicriteria decision problems.

Combination of DEA and GRA was successfully implemented in many fields by Markabi (2014), Pakkar (2016), Kucukonder (2019), Si (2019), Tsolas (2019). etc. Pakkar (2016) used GRA to obtain data that will use as input data for DEA with purpose of selecting dispatching rules. Relaying to his work, this research represents the first attempt to implement following methodology to address road safety of territory and to test it in the field of evaluation of road safety at micro level.

\section{Methodology}

Grey relation analysis is a useful method to solve multiple attributes problem in an uncertain environment. Normalization as first step is conducted with:

$g_{i}(j)=\frac{x_{i}(j)-\min _{j=1}^{n} x_{i}(j)}{\max _{i=1}^{n} x_{i}(j)-\min _{j=1}^{n} x_{i}(j)} ;$

with $n$ data sequences $(i=1 \ldots n)$ and $m$ attributes $(j=1 \ldots m)$. In this method, the reference sequence is selected from normalized matrix, which means that an 
ideal solution to this problem with the best performance for each of all criteria considered. All the indicator values are compared with the reference sequence based on each of the criteria computing the grey relational coefficient.

$\zeta_{0 i}(\mathrm{j})=\frac{\min _{i=1}^{n} \min _{j=1}^{m}\left|g_{i}(j)-g_{0}(j)\right|+\rho \max _{i=1}^{n} \max _{j=1}^{m}\left|g_{i}(j)-g_{0}(j)\right|}{\left|g_{i}(j)-g_{0}(j)\right|+\rho \max _{i=1}^{n} \max _{j=1}^{m}\left|g_{i}(j)-g_{0}(j)\right|} ;$

where $\rho$ is the distinguishing coefficient $[0,1]$ and in most situations this value is 0.5 because it offers moderate distinguishing effects. Grey relation analysis can calculate the degree of similarity to the reference based on the grade of relation as follows:

$\Gamma_{0 i}(\mathrm{j})=\frac{1}{n} \sum_{j=1}^{m} \zeta_{0 i}(\mathrm{j})$;

Based on the grey relational degrees, the indicator with the highest degree of relation can be identified as the most influencing. Data Envelopment Analysis (DEA), defining efficiency of Decision Making Unit (DMU) as ratio of sum of the weighted outputs and sum of the weighted inputs and DMU is called efficient when ratio is equal to 1. Linear formulation is given as follows:

$\operatorname{maxEf}=\sum_{r=1}^{s} u_{r} y_{r j}$

Subject to:

$\sum_{i=1}^{m} v_{i} x_{i j}=1$

$\sum_{r=1}^{s} u_{r} y_{r j} \leq \sum_{i=1}^{m} v_{i} x_{i j}, j=1, \ldots, n$

$u_{r} \geq \varepsilon ; r=1, \ldots, s$

$v_{i} \geq \varepsilon ; \quad i=1, \ldots, m$

where $y_{r j}$ stands for output and $x_{i j}$ stands for $i^{\text {th }}$ input of the $j^{\text {th }}$ decision making unit, $u_{r}$ is the weight of the output $r, v_{i}$ is the weight for the input $I$ and $\varepsilon$ is really small number and its purpose is to assure non-negative and non-zero weights.

In this paper, GRA is used to obtain input and output values for DEA model in order to obtain efficiencies of 21 Montenegro municipalities and cross-efficiency (CE) is used for the final ranking.

\section{Data}

To get usable results with DEA, Alper et al. (2015) highlights that the following rule must be satisfied:

$3 \times$ (No. of Inputs + No. of Outputs) $\leq$ No. of DMUs

Table 1. Description of input and output data

\begin{tabular}{lllcc}
\hline Data set & Id & Indicators & Avg. & St. Dev. \\
\hline Input & I1 & Speed & 727,67 & 2089,16 \\
& I2 & Alcohol/drug & 377,24 & 544,02 \\
& I3 & Seatbelt & 75,90 & 158,41 \\
& I4 & Mobile phone & 2818,90 & 2661,71 \\
Output & I9 & Number of accidents & 327,43 & 589,19 \\
& I10 & Number of fatalities & 3,19 & 2,87 \\
\hline
\end{tabular}

Respecting that, four road safety indicators were selected as inputs and two outcomes for outputs. These road safety indicators were selected in order to calculate safety performance of 21 municipalities (see Table 1). Given the lack of availability of road safety data in Montenegro, authors of this paper chose traffic violations as Antić et al. (2020) suggested. Considering road safety, outputs should be as low as possible and in order to address this issue, inputs and outputs data in DEA model are reciprocal values.

\section{Results}

The data envelopment analysis leads up to DMUspecific outcomes. Within the bounds of the equality and inequality constraints the most optimal weights are chosen creating a road safety score as close to one as possible. Finally, DEA yields the results of a ranking based on the optimal road safety score, and based on the cross efficiency score. Obtained performance scores as well as the corresponding rankings and Mavericks are presented in Table 2.

Table 2. Results of grey DEA and regular DEA model

\begin{tabular}{lrrrrc} 
& \multicolumn{3}{c}{ Grey DEA } & \multicolumn{3}{c}{ Grey Cross-efficiency } \\
\cline { 2 - 6 } & Score & Rank & Score & Rank & \multicolumn{1}{c}{ M ${ }^{*}$} \\
\hline PV & 1,000 & 1 & 0,775 & 5 & 0,290 \\
RO & 1,000 & 1 & 0,876 & 4 & 0,141 \\
AN & 1,000 & 1 & 0,986 & 1 & 0,014 \\
PG & 1,000 & 1 & 0,886 & 3 & 0,129 \\
UL & 1,000 & 1 & 0,931 & 2 & 0,074 \\
ŻA & 0,892 & 6 & 0,324 & 20 & 1,758 \\
TV & 0,765 & 7 & 0,561 & 6 & 0,365 \\
BD & 0,546 & 8 & 0,502 & 7 & 0,087 \\
Š & 0,538 & 9 & 0,497 & 8 & 0,081 \\
KL & 0,520 & 10 & 0,494 & 9 & 0,053 \\
PŽ & 0,510 & 11 & 0,471 & 10 & 0,083 \\
BR & 0,502 & 12 & 0,450 & 12 & 0,117 \\
BP & 0,483 & 13 & 0,450 & 11 & 0,073 \\
BA & 0,476 & 14 & 0,445 & 14 & 0,070 \\
DG & 0,475 & 15 & 0,447 & 13 & 0,064 \\
NK & 0,459 & 16 & 0,430 & 15 & 0,067 \\
CT & 0,458 & 17 & 0,430 & 16 & 0,066 \\
PL & 0,431 & 18 & 0,407 & 17 & 0,058 \\
HN & 0,426 & 19 & 0,398 & 18 & 0,068 \\
KO & 0,410 & 20 & 0,371 & 19 & 0,103 \\
MK & 0,380 & 21 & 0,276 & 21 & 0,376
\end{tabular}

\begin{tabular}{|c|c|c|c|c|c|}
\hline & \multicolumn{2}{|c|}{ Traditional DEA } & \multicolumn{3}{|c|}{ Traditional Cross-efficiency } \\
\hline & Score & Rank & Score & Rank & $M l^{*}$ \\
\hline PV & 1,000 & 1 & 0,576 & 7 & 0,738 \\
\hline RO & 0,241 & 19 & 0,148 & 19 & 0,632 \\
\hline AN & 0,780 & 13 & 0,243 & 18 & 2,211 \\
\hline PG & 1,000 & 1 & 0,554 & 10 & 0,806 \\
\hline UL & 0,764 & 14 & 0,386 & 15 & 0,978 \\
\hline ŽA & 1,000 & 1 & 0,688 & 4 & 0,453 \\
\hline TV & 1,000 & 1 & 0,639 & 6 & 0,566 \\
\hline $\mathrm{BD}$ & 0,820 & 12 & 0,504 & 12 & 0,626 \\
\hline SA & 1,000 & 1 & 0,453 & 13 & 1,206 \\
\hline $\mathrm{KL}$ & 0,229 & 21 & 0,093 & 20 & 1,456 \\
\hline PŽ & 0,232 & 20 & 0,082 & 21 & 1,817 \\
\hline $\mathrm{BR}$ & 1,000 & 1 & 0,805 & 1 & 0,242 \\
\hline $\mathrm{BP}$ & 0,698 & 15 & 0,527 & 11 & 0,325 \\
\hline BA & 1,000 & 1 & 0,794 & 2 & 0,259 \\
\hline DG & 0,683 & 16 & 0,432 & 14 & 0,580 \\
\hline NK & 0,493 & 18 & 0,317 & 17 & 0,554 \\
\hline CT & 0,605 & 17 & 0,363 & 16 & 0,668 \\
\hline PL & 1,000 & 1 & 0,687 & 5 & 0,456 \\
\hline $\mathrm{HN}$ & 1,000 & 1 & 0,575 & 9 & 0,738 \\
\hline KC & 1,000 & 1 & 0,575 & 8 & 0,738 \\
\hline$M$ & 1,000 & 1 & 0,784 & 3 & 0,275 \\
\hline
\end{tabular}


With proposed grey DEA methodology five municipalities are identified as best-performing (PV, RO, AN, PG, UL). However, with traditional DEA model, score equal to one derived eleven municipalities, which is a half of the number under evaluation. This indicates more distinguished power among municipalities with grey DEA model. CE score is more representative than the DEA score as all the elements of the cross efficiency matrix are included in it. With both, DEA and CE ranking, AN remain efficient municipality and top five municipalities with DEA stayed at first five places with $\mathrm{CE}$ ranking. That confirms realistic weights assigned to inputs and outputs in equation (1). Placed at bottom of CE scale, conclusion was made that ZA municipality received unrealistic weights in order to achieve its efficiency score of 0.892. Consequently, mentioned municipality obtained the largest Maverick score (1.758) indicating that the DEA efficiency value score deviates from its cross efficiency value by $175 \%$. Closer look at Table 2 shows smaller divergence between DEA and CE scores when grey relation analysis is conducted priory on data.

The proposed approach provides a more reasonable and encompassing measure of performance, based on which the overall ranking position of municipalities is obtained. By grey DEA scores, MK is considered as the worst-performing municipality, while it is considered as efficient with traditional DEA. Four worst-performing with grey based DEA are also considered efficient with traditional DEA. However, their Maverick scores are larger when traditional DEA are applied which indicates unrealistic weight allocation in order to obtain efficiency of one. At the same time, Mavericks are small when grey DEA is applied.

Table 3. Assigned weights of road safety indicators

\begin{tabular}{|c|c|c|c|c|c|}
\hline \multirow{2}{*}{$\begin{array}{l}\text { Data } \\
\text { set }\end{array}$} & \multirow[t]{2}{*}{ Indicators } & \multicolumn{2}{|c|}{ Grey DEA } & \multicolumn{2}{|c|}{ Traditional DEA } \\
\hline & & $\begin{array}{c}\text { Avg. } \\
\text { Weights }\end{array}$ & $\%$ & $\begin{array}{c}\text { Avg. } \\
\text { Weights }\end{array}$ & $\%$ \\
\hline \multirow[t]{4}{*}{ Input } & Speed & 0,207 & 5,18 & 157,153 & 9,67 \\
\hline & Alcohol/drug & 0,382 & 9,56 & 63,043 & 3,88 \\
\hline & Seatbelt & 0,278 & 6,95 & 34,672 & 2,13 \\
\hline & Mobile phone & 1,987 & 49,79 & 1331,423 & 81,93 \\
\hline \multirow[t]{3}{*}{ Output } & Number of & & & & \\
\hline & $\begin{array}{l}\text { accidents } \\
\text { Number of }\end{array}$ & 0,646 & 16,19 & 37,225 & 2,29 \\
\hline & fatalities & 0,492 & 12,32 & 1,645 & 0,10 \\
\hline
\end{tabular}

With the fact that data envelopment analysis relays on choosing different sets of weights for each municipality with the only purpose of maximizing the relative performance, analyzing allocated weights insight can be gained into the relative importance of the inputs and outputs. The assigned weights (Table 3 ) imply that input referring to use of mobile phone while driving should be given priority over the other since the highest share of weight is allocated to this indicator $(49.79 \%$ and $81.93 \%$ with grey DEA and traditional DEA, respectively). Weight allocation can be observed for each municipality and policies can be conducted for each municipality separately, based on its own weight allocation.

\section{Conclusion}

The integration of Grey relational analysis and DEA was presented in this paper. This is the first use of proposed approach for evaluating road safety performance. Six indicators were presented to calculate relative efficiency and rank municipalities. As results, five municipalities which are best-performing and identified and the worst one where should be put great effort to increase road safety.

Additionally, cross efficiency method was introduced to further distinguish municipalities. Doing this, it makes comparison between municipalities more justly. Assigned weights were analyzed and the strategies made by such a process can be adopted either by the government authorities or individually on a local basis. Conclusion is made that the DEA based GRA presented here introduces new insights in road safety relative efficiency considering usage of simple data.

However, results show that some limitations still exist in the application of this approach. Since grey relational analysis is normalization-based methodology, the calculated results might vary based on type of normalization and further research should investigate the normalization method that best fits the data representing road safety. Also, the results obtained from this model are sensitive to the number of municipalities; therefore, extensions of DEA should be investigated to overcome this issue. The progress of the municipalities could be quantified because model is suitable for comparisons over time as well and restrictions for the weight distribution can be added.

\section{References}

[1] Alper, D., Sinuany-Stern, Z. and Shinar, D. (2015). Evaluating the efficiency of local municipalities in providing traffic safety using the Data Envelopment. Accident Analysis and Prevention, 78, 39-50.

[2] Antić, B., Grdinić, M., Pešić, D. and Pajković, V. (2020). Benchmarking of the road safety performance among the regions by using DEA. Transportation Research Procedia, 45, 78-86.

[3] Banker, R.D., Charnes, A. and Cooper, W.W. (1984). Some models for estimating technical and scale inefficiencies in data envelopment analysis. Manage. Sci. 30, 1078-1092.

[4] Charnes, A., Cooper, W.W. and Rhodes, E. (1978). Measuring the efficiency of decision making units. European. Journal of Operation Research, 2, 429-444.

[5] Deng, J. (1989) Introduction to grey system theory. The Journal of Grey System. 1(1), 1-24.

[6] ETSC, European Transport Safety Council (2019) Ranking EU progress on road safety, 13th Road Safety Performance Index Report, Brussels. 
[7] ETSC, European Transport Safety Council. (2011). 2010 Road Safety Target Outcome: 100,000 fewer deaths since 2001. 5th Road Safety PIN Report, Brussels.

[8] European Commission. (2018). Road Safety in the European Union - Trends, statistics and main challenges. Available from:

https://ec.europa.eu/transport/road_safety/sites/roadsafety/fil es/vademecum_2018.pdf

[9] European Commission. (2019). 2018 road safety statistics: what is behind the figures? Available from: https://ec.europa.eu/commission/presscorner/detail/en/MEM O_19_1990

[10] Ministry of interior. (2009). Strategy for improvement of road traffic safety 2010-2019. Podgorica.

[11] World Health Organization. (2018). Global status report on road safety. License: CC BYNC-SA 3.0 IGO. ISBN 978-92-4156568-4. Geneva.

[12] Markabi, M.S., Sabbagh, M. (2014). A Hybrid Method of GRA and DEA for Evaluating and Selecting Efficient Suppliers plus a Novel Ranking Method for Grey Numbers. Journal of Industrial Engineering and Management, 7(5), 1197-1221.

[13] Pakkar, M.S. (2016) Multiple attribute grey relational analysis using DEA and AHP. Complex \& Intelligent Systems. 2, 243250.

[14] Kucukonder, H., Demirarslan, P.C., Burgut, A., Boga M. (2019) A Hybrid Approach of Data Envelopment Analysis Based Grey Relational Analysis: A Study on Egg Yield. Pakistan journal of zoology, 51(3). 903-912.

[15] Si, Q., Ma, Z. (2019) DEA Cross-Efficiency Ranking Method Based on Grey Correlation Degree and Relative Entropy. Entropy, 21, 966.

[16] Tsolas I.E. (2019) Utility Exchange Traded Fund Performance Evaluation. A Comparative Approach Using Grey Relational Analysis and Data Envelopment Analysis Modelling. International Journal of Financial Studies, 7, 67. 